\title{
O avanço do processo de matematização na academia brasileira de economia desde a década de 1980
}

\section{MAURICIO LUPERI*}

The advance of the mathematization process in the Brazilian academy of Economics since the 1980s.

Looking at the economic discourse, we try to study in this article how has mathematization in economics advanced in Brazil in the last three decades. To see this, we have classified into several categories all articles published in three major economic journals of the country (Revista Brasileira de Economia, Estudos Econômicos and Revista de Economia Politica) and the publications made in the meetings ANPEC from 1981 to 2010, according to the type of argument used. The total of articles analyzed adds up to 5.733. We try to see how the path of economic discourse, making it more mathematical, did develop. We found that there was an increased use of a formalized language from the mid-1990s onwards. Finally, to confirm our findings, we focus on the process of mathematization through the observation of quantitative variable: equations per article.

Keywords: mathematization; process; discourse.

JEL Classification: B29; B41.

\section{INTRODUÇÃO}

Aplaudido pela maioria dos economistas, criticado por alguns, o avanço do uso da linguagem matemática em economia a partir da segunda metade do século passado é algo que não parece passível de controvérsias quanto à sua veracidade. Alguns excelentes autores têm estudado esse processo como um todo, ou focalizado pontos específicos. Os economistas que defendem o processo de matematização em geral o assumem como parte natural da consolidação da ciência, e pouco se preo-

* Escola Paulista de Economia, Política e Negócios, Unifesp - Universidade Federal de São Paulo. E-mail: mluperi@gmail.com. Submetido: 16/outubro/2012; Aprovado: 14/fevereiro/2014. 
cupam atualmente em justificar sua necessidade ou conveniência (uma exceção, provocada pelo pedido explícito dos editores de uma polêmica, é Krugman, 1998; uma defesa da formalização que pode ser vista como mais teórica e menos pragmática encontra-se em Katzner, 1991) ${ }^{1}$. Ao contrário, os opositores dessa abordagem têm escrito com frequência para criticar os limites da mesma (veja-se, entre outros, Ward, 1975; Woo, 1986; McCloskey, 1991; Gillies, 2004)².

A centralidade da formalização matemática na economia ortodoxa contemporânea é tal que Colander, Holt e Rosser (2004) entendem que mesmo os economistas mais abertos do "mainstream", que podem abrir mão de qualquer ponto teórico da economia tradicional, consideram que aquilo que não é formalizado não é economia.

Esse processo de matematização na academia internacional foi muito bem estudado no artigo "The When, the How and the Why of Mathematical Expression in the History of Economic Analysis" de Philip Mirowski (1991). Nesse texto, Mirowski considera que houve duas grandes rupturas no processo de matematização do discurso econômico. A primeira ruptura ocorreu entre 1870 e 1890 com a Revolução Neoclássica. Seus principais formuladores (entre eles Walras, Jevons, Fisher, Edgeworth e Pareto), formados majoritariamente em engenharia, teriam feito uma simples adaptação de modelos vindos da física de meados do século XIX, baseada no princípio de conservação de energia ${ }^{3}$. A segunda ruptura no discurso econômico ocorreu entre 1925 e 1935, processo que pode ser atribuído à entrada de um grupo de físicos, notadamente Tinbergen e Koopmans, que mudaram novamente o estilo de se trabalhar em economia. Mirowski estudou esse processo analisando a mudança no discurso econômico em quatro das principais revistas da época: a Revue D'Économie Politique (RDP), o Economic Journal (EJ), o Quartely Journal of Economics (QJE), e o Journal of Political Economy (JPE).

Para analisar a segunda ruptura, Mirowski analisou dados qualitativos dos artigos publicados por esses periódicos de 1887 a 1955 . O autor verificou que, de 1887 a 1924, a presença do discurso matemático nas revistas estudadas era muito parecida, com uma taxa de crescimento próxima de zero. As revistas raramente devotavam mais de $5 \%$ de seu espaço ao discurso matemático até 1924. A mudança no discurso econômico teria ocorrido entre 1925 e 1936.

Entre os periódicos estudados, essa mudança foi liderada pelo QJE, que devotou sistematicamente mais de $20 \%$ do total de páginas ao discurso econômico matematizado a partir de 1940, aproximadamente. No JPE, esse processo demorou um pouco mais, chegando somente nos anos 1950 ao mesmo patamar do QJE. Por

\footnotetext{
${ }^{1}$ Neste artigo, tomaremos os termos formalização, matematização e axiomatização como sinônimos; embora tenham significados diferentes (veja-se Weintraub, 1998), o processo de aumento do uso da linguagem matemática também é o avanço de cada uma dessas abordagens.

${ }^{2} \mathrm{O}$ artigo de Beed e Kane (1991) apresenta um balanço das vantagens e desvantagens da formalização em economia.

${ }^{3}$ Mirowski desenvolveu essa análise com todo detalhe em um trabalho anterior (Mirowski, 1989).
} 
sua vez, o EJ e a RDP só chegam ao índice de $20 \%$ quando a década de 1950 se encontrava bem avançada.

Inspirados em Mirowski, buscamos verificar como se deu o avanço do processo de matematização da economia na academia brasileira. Dado o caráter mais recente da aparição da ciência econômica no Brasil, imaginamos como ponto de partida que esse processo deva ter ocorrido muito mais tarde. Com efeito, embora sempre houvesse economistas práticos no Brasil, os primeiros cursos formais de economia só datam da década de 1940. Em nível de pós-graduação, embora houvesse algumas iniciativas isoladas no Rio de Janeiro e em São Paulo no começo dos anos 1960, só em 1966, com o seminal Encontro de Itaipava, começou a surgir a ideia do que viria a ser a Associação Nacional dos Cursos de Pós-Graduação em Economia - ANPEC (Seminário da USP, 1996). Por sua vez, o primeiro encontro anual da ANPEC só ocorreria em 1973. Ao mesmo tempo, a Sociedade Brasileira de Econometria - SBE, defensora de uma abordagem exclusivamente formalizada, só seria criada em $1979^{4}$.

As perguntas que nos fazemos no começo do estudo são: será que houve algum ponto de ruptura no estudo da economia na academia brasileira no que diz respeito à questão da formalização? Se houve, quando isso teria ocorrido? E, embora isto certamente seja ainda mais difícil de determinar, quais suas causas?

A princípio, apresentamos nossas definições e metodologia para num momento posterior fazer a análise dos dados quantitativos.

\section{METODOLOGIA E DEFINIÇÕES}

Para efetuar este estudo, foi pesquisado o universo de artigos publicados em três das principais revistas de teoria econômica brasileiras: a Revista Brasileira de Economia (RBE), a Estudos Econômicos (EE) e a Revista de Economia Política $(R E P)$ no período de 1981 até 2010 , todas com nota Qualis B2, que é a mais alta concedida pela CAPES a uma revista nacional ${ }^{5}$. Todas têm periodicidade trimestral. Também foram analisados os artigos apresentados nos encontros anuais da ANPEC, realizados nesse mesmo período ${ }^{6}$. O total de artigos verificados foi de 5.733 .

\footnotetext{
${ }^{4}$ Segundo informações constantes no site da própria sociedade, http://bibliotecadigital.fgv.br/ocs/index. php/sbe/index/schedConfs/archive, acesso em 2/3/2012.

${ }^{5} \mathrm{O}$ Qualis é um ranking produzido pela CAPES, a agência do governo federal que supervisiona o ensino de pós-graduação no Brasil. Ele classifica as revistas acadêmicas para efeito da avaliação nacional dos programas de pós-graduação em economia.

${ }^{6}$ Nossa análise baseou-se em revistas e congressos que apresentam um amplo leque de abordagens. Decidimos não estudar, apesar de sua importância, os congressos da Sociedade Brasileira de Econometria e a publicação oficial dessa entidade, atualmente denominada Brazilian Review of Econometrics, pois supõe-se que desde o começo ela deve defender uma abordagem matematizada. Se nosso interesse está em estudar o processo de matematização da academia brasileira de economia em seu conjunto, não fez sentido considerar um grupo cujo recorte, desde seu começo, está dado pela defesa da abordagem
} 
A $R B E$ é a mais antiga revista de economia do país, tendo seu primeiro volume editado em 1947, e a segunda mais antiga da América Latina (a primeira é El Trimestre Económico, cujo primeiro número foi publicado em 1934). Atualmente sua linha de publicação é voltada para artigos mais neoclássicos e, supõe-se, portanto, mais matematizados.

A EE foi criada em 1971 e em princípio é uma revista mais plural, ou seja, suas publicações possuem artigos tanto da corrente neoclássica como de diversas visões da heterodoxia; publica artigos das mais diversas áreas em economia.

A REP foi criada em 1981 e publica trabalhos de economia política dentro de um espírito pluralista. Segundo sua orientação editorial, não considerará para publicação trabalhos de economia pura excessivamente abstratos, logo essas características permitem supor que em geral os artigos devam ser menos matematizados.

Os Encontros da ANPEC são realizados anualmente desde 1973 e têm

[...] o objetivo de estimular o intercâmbio entre economistas e profissionais de áreas afins. [...] Durante o Encontro, são apresentados trabalhos inéditos selecionados por uma equipe designada para tal fim. Os textos exploram as fronteiras do conhecimento científico na teoria econômica, na economia política e na econometria. Há também a preocupação com a discussão da realidade nacional, que é objeto de painéis e sessões temáticas, além de temas de interesse regional. O evento conta também com a participação de renomados pesquisadores estrangeiros. (Encontro Nacional de Economia, 2012)

Nos Encontros da ANPEC são apresentados artigos das mais diversas áreas da Economia. Os encontros podem ser considerados plurais, e os trabalhos são selecionados por comitês formados por representantes dos diversos centros que compõem seu Conselho Deliberativo ${ }^{7}$.

Os artigos encontrados nas três revistas e nos Encontros da ANPEC foram classificados em seis categorias:

i. artigos sem formalização e com poucos (ou nenhum) dado, utilizando fundamentalmente linguagem natural;

ii. artigos teóricos cuja argumentação está baseada fundamentalmente em formalizações matemáticas, com pouco ou sem nenhum tipo de apresentação de dados (artigos com simulações foram incluídos aqui também);

iii. artigos sem modelagem formal nem econometria, mas que utilizam dados (p.ex., estatística descritiva) como centro de sua argumentação;

\footnotetext{
formalizada. Espera-se que a percentagem de artigos formalizados nessa vertente seja de $100 \%$ do começo ao fim do período em análise.

${ }^{7} \mathrm{O}$ caráter dos encontros como um todo é plural; muitas vezes os comitês de seleção de alguma área específica apresentam forte viés metodológico ou ideológico.
} 
iv. artigos em que existe com destaque alguma seção teórica formalizada, porém há no mínimo alguma parte empírica baseada na econometria;

v. artigos em que prevalece a econometria sobre a teoria (tipicamente, artigos sem modelo teórico, ou com uma breve discussão do modelo, mas no qual a argumentação do trabalho é essencialmente econométrica);

vi. artigos em que existe alguma seção teórica formalizada, porém há no mínimo alguma parte empírica baseada em estatística descritiva.

Consideramos estatística descritiva, a estatística que utiliza tabelas com dados absolutos ou percentuais, índices, gráficos, etc. mas nos quais não há praticamente inferência estatística, etc.

Os dados coletados desde 1981 até 2010 são apresentados consolidados por ano e por veículo (as três revistas e os encontros da ANPEC) e se referem:

vii. ao número de artigos por categoria;

viii. ao número de páginas por categoria; $\mathrm{e}$

ix. ao número de equações por ano dentro de cada revista pesquisada e nos encontros da ANPEC.

A coleta de informações primárias foi feita na biblioteca da FGV-SP, nos sites das revistas em questão, no site da ANPEC e em um DVD que inclui todos os artigos apresentados nos encontros da ANPEC até o ano de 2009. Cada artigo foi avaliado e classificado em uma das seis categorias. Como em toda tipologia que impõe uma classificação discreta a uma realidade contínua, ou melhor ainda, plurifacetada, alguns artigos não se encaixavam perfeitamente em um dos seis nichos. Esses casos foram incluídos na categoria que, após uma detida análise do artigo, se considerou que captava melhor o espírito do mesmo ${ }^{8}$.

Feita a classificação dos artigos, definimos como avançou o processo de matematização na academia brasileira de economia, com o entendimento de que esse avanço se deu mediante o crescimento da publicação dos artigos tipo ii, iv e v. Portanto, definimos os artigos do tipo i, iii e vi como sendo menos matematizados.

Nossas definições procuram abordar tanto aspectos qualitativos quanto quantitativos. Nesse sentido, nossa análise diferencia-se daquela feita por Mirowski (1991), que considera a análise de variáveis quantitativas, como por exemplo, o número de equações por página, um indicador insuficiente para verificar esse processo de matematização. Ao final, observamos se há correlação entre esses dois tipos de variáveis no que se refere à(s) ruptura(s) no discurso econômico.

\footnotetext{
${ }^{8}$ Sem nos determos muito na questão e dando um único exemplo: basta uma tabela num artigo de 20 páginas para fazer com que este passe da categoria i) para a iii)? Tanto faz se essa tabela é longamente discutida, ou se só recebe uma observação en passant no começo do artigo sem ser retomada? Esses tipos de decisões não podem ser decididas por um algoritmo, mas tem de ser avaliadas pelo pesquisador no momento de realizar a classificação.
} 


\section{ANÁLISE DAS PUBLICAÇÕES SEGUNDO O TIPO DE ARTIGOS}

Inicialmente, observamos como se deu a evolução da publicação de cada um dos tipos de artigos categorizados dentro de cada revista e nos encontros da ANPEC. Num momento posterior, segundo nossas definições, analisamos os dados de maneira agregada.

Nossa análise começou pela verificação da porcentagem de artigos por tipo na Revista de Economia Política (REP). Observamos que os artigos do tipo i apresentam grande variação na década de 1980 , situando-se entre $30 \%$ e $70 \%$ das publicações da época. Já na década de 1990, verificamos uma redução dessa variação, ficando entre $50 \%$ a $70 \%$ até meados da última década, quando tende a variar entre $40 \%$ e $60 \%$.

Percebemos que há uma queda acentuada na publicação dos artigos do tipo iii a partir do final da década de 1980 . Nesse período, as publicações desse tipo de artigo variavam entre $30 \%$ e $50 \%$, girando entre $20 \%$ e $30 \%$ na década de 1990 e se estabilizando em torno de $20 \%$ na última década.

Por outro lado, não verificamos grandes variações na publicação dos artigos do tipo vi, que permanecem em torno de $0 \%$ e $10 \%$ ao longo das três últimas décadas, em muitos anos são $0 \%$ das publicações. Já os artigos do tipo ii, permanecem estáveis em torno de $0 \%$ e $10 \%$ das publicações, indicando que apenas uma pequena parte dos artigos publicados é constituída pela pesquisa básica formalizada.

No que se refere aos artigos do tipo iv, praticamente não eram publicados na REP na década de 1980, começam a aumentar no inicio da década de 1990, situando-se em torno de $7 \%$ a $10 \%$ até o início da última década, quando passam a variar entre $10 \%$ e $30 \%$ das publicações. Já os artigos mais puramente econométricos (tipo v) partem de um patamar de $0 \%$ na década de 1980 , elevam-se a patamares em torno de $5 \%$ a partir de 1994 e se situam em torno de $10 \%$ desde meados da última década.

Verificamos na REP um declínio mais acentuado da publicação de artigos do tipo iii, fundamentalmente de estatística descritiva.

Por outro lado, observamos uma ascensão de dois tipos de artigos, os do tipo iv (teoria econômica formalizada com econometria) e do tipo $\mathrm{v}$ (econometria com pouca ou quase nenhuma teoria econômica formalizada).

Portanto, vemos certo avanço do processo de matematização na REP. Entretanto, para dimensionar esse avanço é necessário compará-lo com as demais revistas e com os encontros da ANPEC, e é isso que fazemos abaixo.

Vejamos agora o que ocorreu na revista Estudos Econômicos (EE). Nessa revista, os artigos tipo i têm uma variação entre $20 \%$ e $40 \%$ do total na década de 1980, exibindo elevação na década de 1990 , girando em torno de $40 \%$ a $60 \%$, tendo uma queda mais acentuada até metade da última década, ficando entre $20 \%$ e $30 \%$, se estabilizando a patamares de aproximadamente $20 \%$ do total de publicações desde meados do último decênio. Essa trajetória da $E E$, embora siga uma tendência semelhante à da REP nos anos 1980 e 1990, na última década sofre um declínio mais acentuado em relação a esta última. Lembramos que a $R E P$ possui 
variações nas décadas de 1980 e 1990 que giram entre $30 \%$ e $70 \%$ e $50 \%$ e $70 \%$ respectivamente, enquanto que desde meados da última década, a participação nas publicações dos artigos do tipo i se localiza entre $40 \%$ e $60 \%$ do total. Já na EE, apesar da das publicações desse tipo de artigo terem subido de maneira considerável dos anos 1980 para os noventa (entre $20 \%$ e $40 \%$ para entre $40 \%$ e $60 \%$ respectivamente), no final da década de 1990, começa a haver um declínio acentuado, seguindo uma tendência de estabilização a patamares muito inferiores em relação à $R E P$, por volta de $20 \%$ (EE) contra 40 a $60 \%$ (REP) das publicações.

No que se refere aos artigos do tipo iii, verificamos na $E E$ um declínio um pouco mais acentuado do que o visto na REP (aproximados $20 \%$ na última década) a partir do final da década de 1990, mas que segue a mesma tendência. Observamos que esse tipo de artigo girava em torno de 30 a $60 \%$ do total de publicações na década de 1980 , reduzindo-se a $30 \%$ e $50 \%$ até meados da década de 1990 , caindo a patamares em torno de $10 \%$ no final desse mesmo decênio, estabilizando-se desde então nesse patamar até 2010. Por outro lado, não verificamos grandes variações na publicação dos artigos do tipo vi, que permaneceram em torno de $0 \%$ e $10 \%$ ao longo das três últimas décadas em muitos anos sendo $0 \%$ das publicações. O mesmo ocorre com os artigos do tipo ii, permaneceram estáveis em torno de $10 \%$ das publicações, com certo declínio na década de 1980. Mais uma vez, assim como na $R E P$, observamos que os artigos publicados na $E E$ que envolvem pesquisa básica formalizada são a minoria.

Já os artigos do tipo iv da EE situam-se ao redor de $10 \%$ do início década de 1980 até o final da década de 1990, quando passam ao patamar de 20 a $30 \%$ do total de publicações nessa revista. A mesma tendência ocorre com os artigos do tipo v, o que indica avanço do processo de matematização da economia, segundo nossas definições, nessa revista.

$\mathrm{Na}$ sequência, ao fazermos a análise dos dados da Revista Brasileira de Economia $(R B E)$, percebemos, que os artigos publicados do tipo i na $R B E$, na década de 1980 , situam-se em torno de 10 a $30 \%$, patamar inferior tanto ao da $R E P$ quanto ao da $E E$. Entretanto, na $R B E$, assim como nas outras revistas, esse tipo de artigo, em que prevalece a linguagem natural, sofre um elevação nos anos 1990, situando-se em torno de $20 \%$ e $40 \%$ do total de publicações. Entretanto, ao final dessa década começa haver uma queda acentuada da aceitação desses artigos menos matematizados, ficando entre $0 \%$ e $10 \%$ no início da última década e chegando $0 \%$ nos últimos três anos. Verificamos que, assim como na EE, existe uma tendência de queda na publicação dos artigos do tipo i na $R B E$, o que ocorre de maneira mais radical nos últimos anos.

No que se refere aos artigos do tipo iii, verificamos a mesma tendência de queda na publicação ocorrida tanto na REP quanto na $E E$. Na década de 1980, os artigos que possuem estatística descritiva como fundamento se situavam em torno de 10 a 30\%, caíram para aproximadamente $10 \%$ na década de 1990 e próximo a $0 \%$ das publicações na $R B E$ a partir de meados da década passada.

Por outro lado, não verificamos grandes variações na publicação dos artigos do tipo vi, que permanecem em torno de $0 \%$ e $10 \%$ ao longo das três últimas décadas. 
Já os artigos do tipo ii, com teoria formal básica, situam-se entre $10 \%$ e $30 \%$ na década de 1980 , entre $10 \%$ e $20 \%$ até o final da década de 1990 e se elevam ao mesmo patamar da década de 1980, na última década.

Os artigos do tipo iv tendem a permanecer em torno de $20 \%$ nas décadas de 1980 e 1990, verificando-se uma ascensão para patamares entre $20 \%$ e $30 \%$ das publicações na $R B E$ na segunda metade da última década.

$\mathrm{Na} R B E$, a maior taxa de crescimento de publicação de artigos é a do tipo v, que envolve "econometria pura". Talvez isso tenha ocorrido em função do maior acesso aos computadores pessoais na década de 1990 e aos programas econométricos tais como Eviews, Stata, etc.; daí a queda acentuada de publicações do tipo iii, que utilizam estatística descritiva como fundamento. Os artigos do tipo v, que contribuíam entre $10 \%$ e $30 \%$ das publicações nos anos 1980, passaram a se situar entre $20 \%$ e $30 \%$ na década de 1990 , ascendendo desde o final dessa década para uma faixa entre $30 \%$ e $60 \%$ das publicações até 2010 .

$\mathrm{Na}$ sequência, apresentamos os dados referentes às porcentagens de artigos por tipo nos Encontros da ANPEC. A princípio verificamos que os artigos do tipo i, na década de 1980 , situam-se entre $30 \%$ e $40 \%$, alcançando uma faixa entre $40 \%$ e $45 \%$ do total desde o início até meados da década de 1990, quando sofrem uma queda acentuada, ficando entre $10 \%$ e $15 \%$ das publicações até 2010 .

No que se diz respeito aos artigos tipo iii, denotamos que esse tipo de artigo estava entre $25 \%$ e $30 \%$ dos artigos aceitos pela ANPEC na década de 1980, passando para um patamar de publicação entre $15 \%$ e $25 \%$ durante praticamente toda a década de 1990, quando sofre um decréscimo chegando à última década na faixa entre $5 \%$ e $10 \%$ do total de publicações. Notamos que essa queda segue a mesma tendência da REP, EE e RBE.

Já os artigos do tipo vi, permanecem numa faixa entre $5 \%$ e $10 \%$ nas três últimas décadas, não havendo grande variação percentual de publicação desse tipo de artigo pela ANPEC. Não ocorre também grande mudança na tendência de aceitação pela ANPEC dos artigos do tipo ii. Verificamos que esse tipo de artigo se situa entre $10 \%$ e $15 \%$ dos artigos publicados nas últimas três décadas nos encontros.

Observando os artigos do tipo iv e v, denotamos que existe uma tendência de crescimento acentuada da aceitação desses tipos de artigos pela ANPEC. Apesar de haver uma tendência semelhante à da $E E$, aqui o crescimento da aceitação desses tipos de artigos é mais radical. $\mathrm{O}$ artigo do tipo iv (teoria econômica formalizada com econometria) salta de uma faixa entre $5 \%$ e $15 \%$ na década de 1980 até meados da década de 1990 para, a partir daí, elevar-se continuamente, até se estabilizar em torno de $30 \%$ das publicações na última década. Do mesmo modo, ao observarmos os artigos do tipo v (econometria pura), percebemos que a sua aceitação se situa em torno de 5 a $10 \%$ na década de 1980 até meados da década de 1990, quando começa a haver um crescimento acentuado das publicações, se consubstanciando num patamar entre $30 \%$ e $35 \%$ na última década.

É importante frisar que a maioria dos artigos pesquisados neste capítulo é da ANPEC, do total de 5.733, 3.210 são os apresentados nos encontros dessa instituição. Portanto, quase $56 \%$ dos artigos. Claro que isso tem importância e dá certo 
viés a nossa próxima análise, pois calculamos a variação percentual agregada por tipo de artigo. Além disso, pode haver algum problema de defasagem quanto à publicação, visto que os artigos dos encontros da ANPEC tipicamente são publicados no mesmo ano em que são escritos em sua primeira versão, enquanto os das revistas não são publicados imediatamente; ao contrário, eles têm de enfrentar as negociações entre autores e os pareceristas. E, quando aprovados ainda enfrentam a demora da fila de publicações, o que pode fazer com que se passem alguns anos desde a elaboração de um artigo até sua publicação. Entretanto, ao fazer a análise individualizada, podemos tentar identificar futuramente os possíveis problemas, como a observação de um real ponto de inflexão do discurso econômico na academia brasileira de economia.

Em termos gerais, podemos verificar no Gráfico 1, na análise de todas as revistas mais as publicações nos Encontros da ANPEC, que os artigos do tipo i (linguagem natural) começaram a sofrer uma redução a partir do final da década de 1990. Esse tipo de artigo se situava entre $30 \%$ e $40 \%$ na década de 1980 , elevou-se para um nível entre $40 \%$ e $50 \%$ na década de 1990 , e se estabilizou na última década entre $15 \%$ e $20 \%$ do total. Os artigos do tipo iii sofreram uma queda mais substancial, e nas publicações das últimas três décadas, saíram de uma faixa entre $30 \%$ e $40 \%$ nos anos 1980 , decrescendo a um nível entre $20 \%$ e $30 \%$ na década de 1990 e se estabilizando entre $8 \%$ e $10 \%$ dos artigos que conseguiram ser publicados no último decênio.

Por outro lado, notamos que houve ascensão na publicação, em termos gerais, dos artigos dos tipo iv e v. Os primeiros, giravam em torno de $10 \%$ nos anos 1980 , até o final dos noventa, quando começam a ter um crescimento mais acentuado, localizando-se entre $20 \%$ e $30 \%$ dos artigos publicados na primeira década do novo milênio. Os últimos se situavam entre $0 \%$ e $10 \%$ na década de 1980 até o final dos anos 1990, quando sua taxa de publicação começa a se elevar, chegando a um nível entre $20 \%$ e $30 \%$ na última década. Percebemos, portanto, um crescimento substancial desses dois tipos de artigos somados, passando de patamares entre $10 \%$ e $20 \%$ para $40 \%$ e $60 \%$ das publicações.

Vejamos agora como se deu o avanço do processo de matematização ao comparar os artigos das categorias i, iii e vi, menos matematizados, segundo nossas definições, com os artigos das categorias ii, iv e v, mais matematizados, dentro de cada revista e nos encontros da ANPEC.

Ao analisarmos todos os artigos publicados nas revistas e nos encontros da ANPEC, percebemos que há uma tendência de queda de publicação dos artigos menos matematizados desde a década de 1980 . Na EE e na $R B E$, essa queda se evidencia de maneira mais acentuada ao final dos anos 1990. Na ANPEC, isso ocorre a partir de meados da década de 1990 e na REP no começo da década passada.

Os extremos em termos de tipo publicação são representados pela $R B E$ e pela $R E P$. Nos anos 1980, até o final dos 1990, a RBE publicava entre $40 \%$ e $60 \%$ de artigos menos matematizados, enquanto nos dias de hoje isso não chega muitas vezes a $5 \%$. Por outro lado, na REP entre $80 \%$ a $100 \%$ dos artigos publicados nas 


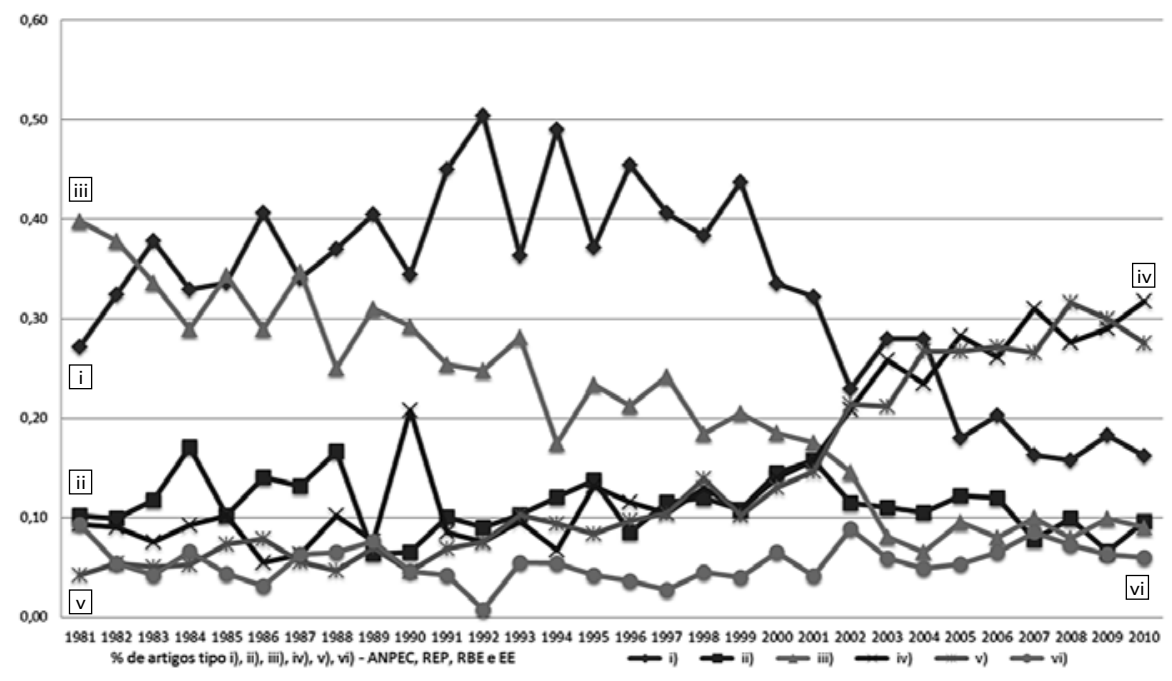

Fonte: REP, EE, RBE, ANPEC, elaboração própria.

décadas de 1980 e 1990 eram menos matematizados, enquanto na última década esse percentual se situou entre $40 \%$ e $60 \%$.

Por outro lado, notamos que, em todas as revistas e nos encontros da ANPEC, há uma tendência ascendente de publicação dos artigos mais matematizados (tipos ii, iv e v) desde a década de 1980. Na EE e na $R B E$, essa ascensão se evidencia de maneira mais acentuada ao final dos anos 1990. Na ANPEC, a elevação desse tipo de publicação ocorre a partir de meados da década de 1990 e na REP, no começo da década passada.

Percebemos que desde o início da década de 1980 a $R B E$ é a revista mais matematizada e a $R E P$, a menos. A primeira apresenta uma elevação mais acentuada de publicações de artigos mais matematizados que a segunda, aumentando a distância entre as duas em termos do que se considera a forma mais adequada de publicação. Nos anos 1980, até o final dos 1990, a RBE publicava entre 40\% e $60 \%$ de artigos mais matematizados, enquanto no último decênio o percentual ficou entre $90 \%$ e $100 \%$ das publicações. Por outro lado na REP, entre 0 a $20 \%$ dos artigos publicados nas décadas de 1980 e 1990 eram mais matematizados, enquanto na última década esse percentual está entre $20 \%$ e $40 \%$.

Observamos que o processo de publicação de artigos mais matematizados encontra uma situação intermediária na EE e nos encontros da ANPEC.

Em termos gerais, quando verificamos todos os artigos de três das principais revistas de economia do país e dos encontros da ANPEC, nas últimas três décadas, é nítido que houve um avanço do processo de matematização dentro da academia brasileira de economia. Para comprovar isso, observamos o Gráfico 2. Pela análise gráfica, por meio de uma categorização qualitativa, os artigos mais matematizados 
(tipo ii, iv e v) saíram de um patamar de $20 \%$ a $30 \%$ desde o começo da década de 1980 para um patamar entre $60 \%$ e $70 \%$ do total das publicações em três das principais revistas de economia do Brasil e nos encontros da ANPEC na última década.

Gráfico 2: Porcentagem de artigos ii), iv) e vi) [mais matematizados] $-R E P+R B E+E E+$ ANPEC

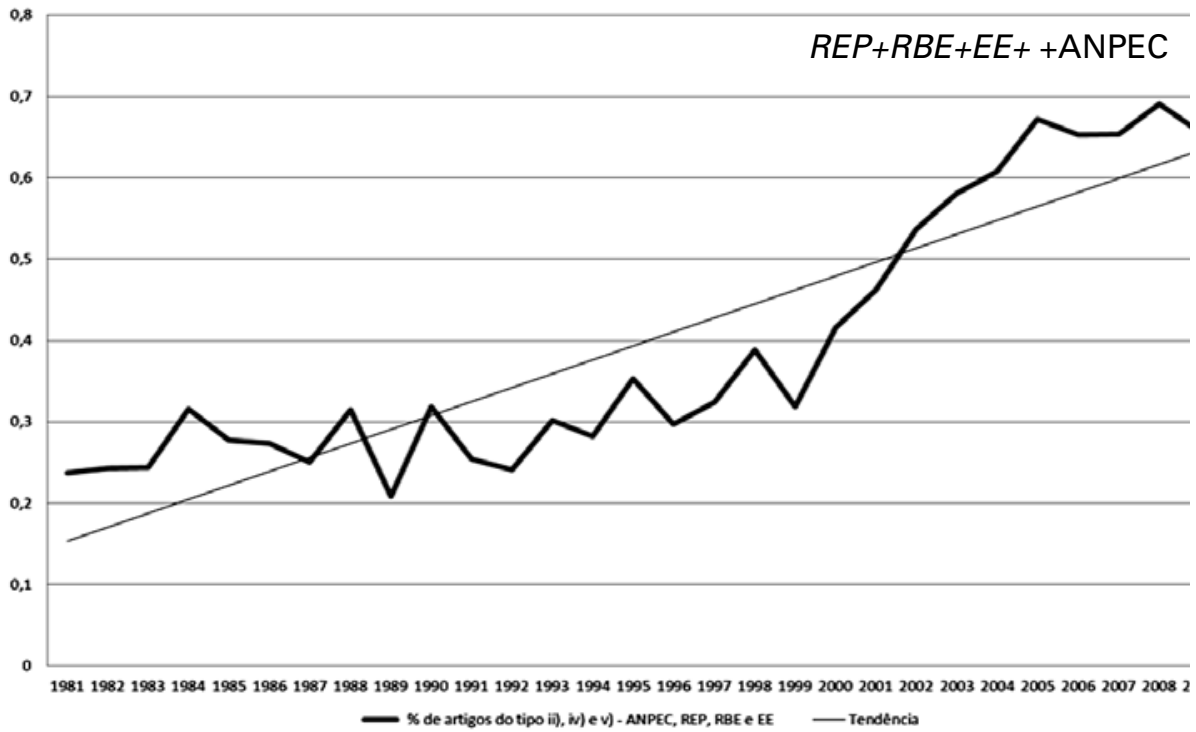

Fonte: $R E P, E E, R B E, A N P E C$, elaboração própria.

Analisando os dados, a princípio o ponto de ruptura no discurso econômico brasileiro parece ter ocorrido em meados dos anos 1990 na ANPEC, embora, nas outras revistas, pareça ter se dado a partir do final da década de 1990. Talvez pelos mencionados motivos de defasagens em relação às publicações, as datas sobre esse ponto de inflexão sejam divergentes.

\section{ANÁLISE DAS PUBLICAÇÕES SEGUNDO A QUANTIDADE DE EQUAÇÕES}

Mirowski (1991) considera a análise do avanço do processo de matematização via aumento de número médio de equações por página um critério insuficiente, pois não aponta o verdadeiro conteúdo do discurso em economia, se mais matemático ou menos; segundo o referido autor, um discurso em linguagem natural pode estar fazendo uso de um estilo mais simpático à formalização do que se manifesta apenas pela observação da quantidade de equações. Sem negar que isso possa acontecer, entendemos que esses casos são bastante atípicos, e por isso procederemos a empregar a quantidade de equações por artigo como proxy do processo de matematização complementando a análise apresentada na seção anterior. 
Por isso, a fim de comprovar a plausibilidade de nossa análise, considerando-a superior, em termos de conteúdo, à simples aplicação da variável quantitativa “equações por página", observamos o que ocorre com o processo de matematização da ciência econômica quando utilizamos esse tipo de variável.

Verificamos que o número médio de equações por artigo da Revista Brasileira de Economia se eleva de uma faixa entre oito e dez na década de 1980 para um patamar entre dez e doze no último decênio, caracterizando um aumento em aproximados $20 \%$ do número de equações nos últimos trinta anos.

Também notamos um aumento do número de equações por artigo na revista Estudos Econômicos. O número de equações sai de uma faixa entre duas e quatro na década de 1980, para quatro e seis nos anos 1990, ficando entre seis e oito no último decênio.

Quando analisamos os dados dos Encontros da ANPEC, também verificamos que existe um movimento de elevação do número de equações por artigo, de um patamar entre três e cinco nos anos 1980, para entre cinco e sete nos anos 1990, chegando a uma faixa entre sete e oito equações na última década.

Mesmo quando analisamos a Revista de Economia Política, que supostamente seria um veículo menos propenso a publicar artigos formalizados, vemos que há uma elevação do número de equações por artigo nas últimas três décadas de um patamar entre uma e duas equações na década de 1980 para uma faixa entre duas e três por artigo no primeiro decênio deste século.

Ao fazer uma comparação entre os quatro tipos de publicações, vemos que apesar de um número menor de equações por artigo na $E E$ em relação à $R B E$, a primeira teve uma aceleração mais acentuada desse tipo de variável se comparada à segunda ao longo das três últimas décadas.

Também verificamos que um movimento semelhante ao da $E E$ ocorreu com os artigos publicados nos Encontros da ANPEC, ou seja, quando comparadas às publicações na $R B E$, a variável em destaque cresce de maneira mais acentuada. Entretanto, tanto da EE quanto nos Encontros da ANPEC, apesar do crescimento mais acentuado da quantidade de equações por artigo em ambas (tendem a ficar entre seis e oito no último decênio), não alcançam o patamar desse tipo de variável na $R B E$ (que tende a ficar entre dez e doze na última década).

Quando observamos a variável em questão na $R E P$, percebemos que o avanço em termos de volume de equações foi bem menos acelerado do que os da $E E$ e da ANPEC. Entretanto, na REP, o aumento em termos relativos de equações praticamente dobrou nos últimos trinta anos (entre uma e duas nos anos 1980 para duas e três na primeira década deste novo milênio). 


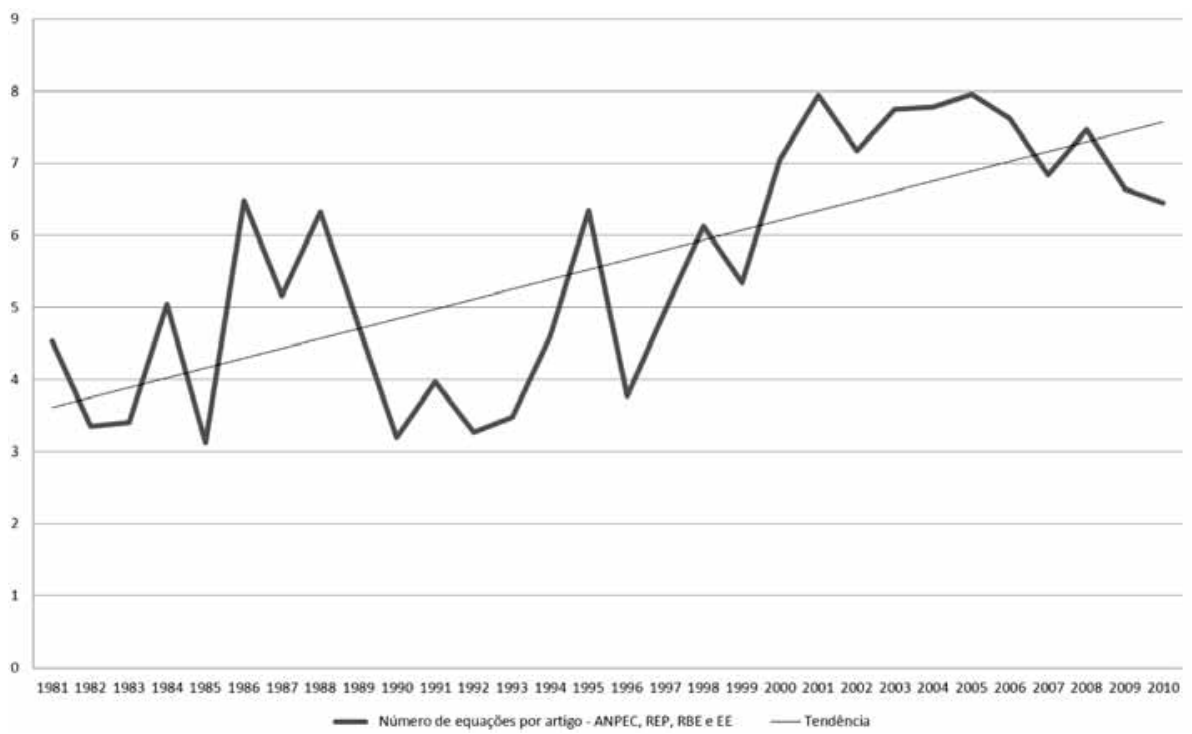

Fonte: $R E P, E E, R B E, A N P E C$, elaboração própria.

Ao considerar todas as revistas mais os encontros da ANPEC, observamos no gráfico 3 que há uma tendência generalizada do processo de matematização da ciência econômica na academia brasileira, via aumento crescente do número médio de equações por artigo, de três a cinco nos anos 1980 para cinco a seis nos anos 1990, situando-se entre seis e oito equações por artigo no último decênio.

\section{CONVERGÊNCIA ENTRE VARIÁVEIS QUALITATIVA E VARIÁVEIS QUANTITATIVAS}

A questão que colocamos é se há uma convergência desse tipo de análise com a variável quantitativa: equações por artigo?

Para verificar isso, no Gráfico 4 sobrepomos ambos os gráficos: porcentagem de artigos tipo ii, iv e v e número de equações por artigo de todas as publicações somadas, procuramos responder a essa questão.

Analisando o Gráfico 4, observamos que de fato há uma convergência das análises tanto do aspecto qualitativo, desenvolvido por nós, quanto do aspecto quantitativo. Sendo nossa análise qualitativa mais rica em detalhes que a mera análise quantitativa, pois podemos avaliar a evolução de cada revista e dos Encontros da ANPEC em termos de categoria de discurso econômico ao longo das últimas três décadas. 
Gráfico 4: Sobreposição número médio de equações por artigo - REP+RBE+EE+ANPEC e porcentagem de artigos TIPO II), IV) E V) - REP+RBE+EE+ANPEC

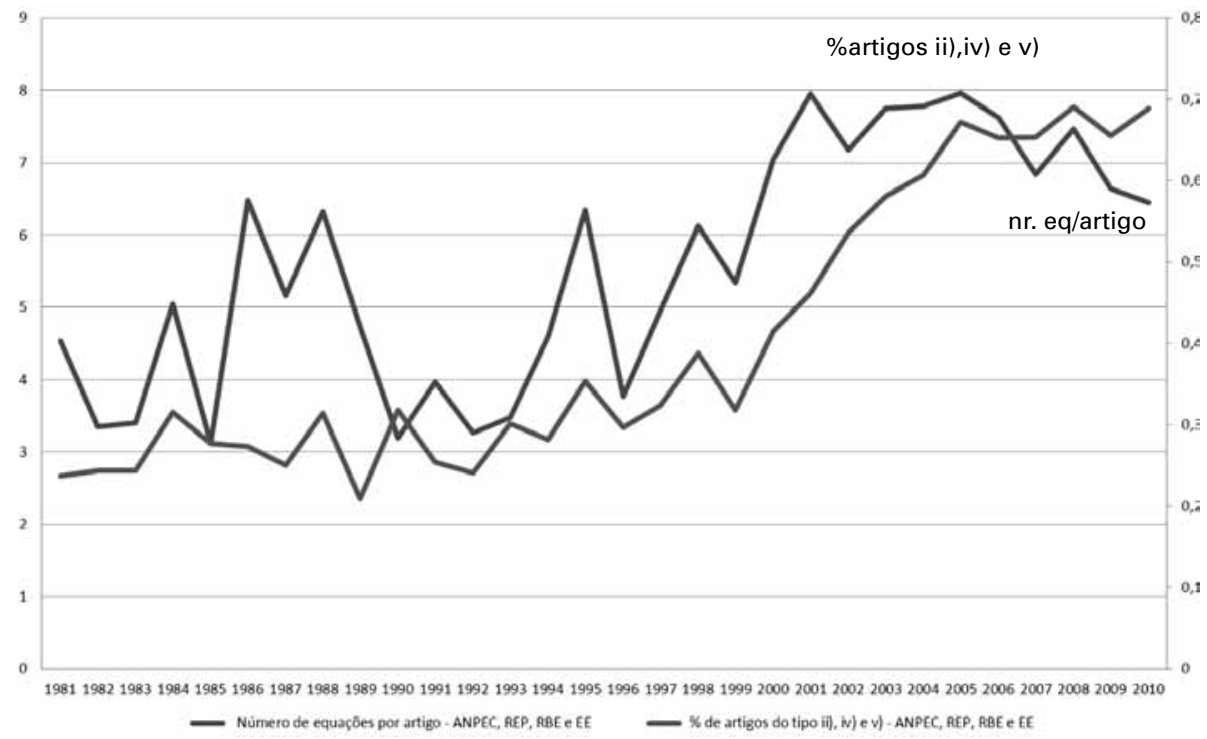

Fonte: $R E P, E E, R B E, A N P E C$, elaboração própria.

\section{O PROCESSO DE AVANÇO DA MATEMATIZAÇÃO: ALGUMAS EXPLICAÇÕES TENTATIVAS}

Faremos nesta seção uma breve discussão tentativa de algumas razões que podem explicar o avanço do processo de matematização na academia brasileira na área de economia nos últimos anos, bem quanto às formas em que este ocorreu. Duas das explicações, que desenvolveremos a seguir, apontam para o progresso técnico, que reduziu drasticamente os custos das análises econométricas, e para as mudanças nos critérios de avaliação da CAPES, que influenciaram as publicações dos pesquisadores vinculados aos centros de pós-graduação no país.

No que se refere ao progresso técnico, a difusão dos microcomputadores e os avanços na velocidade de processamento facilitaram exponencialmente a realização dos cálculos econométricos ${ }^{9}$. A partir do final da década de 1970 as universidades possuíam computadores que podiam fazer cálculos estatísticos, e a partir do final da década de 1980 os diversos cursos de pós-graduação foram montando seus laboratórios de informática, facilitando para professores e alunos o uso de técnicas econométricas antes custosíssimas ou simplesmente inacessíveis. A isso se somou a maior facilidade para aquisição de computadores pessoais a partir da década de

\footnotetext{
${ }^{9}$ Embora não seja nossa preocupação aqui, podemos indicar que o artigo de Renfro (2009) faz uma interessante revisão da evolução dos pacotes econométricos.
} 
1990; para darmos um exemplo, 12,5\% dos domicílios brasileiros possuíam esse tipo de computador em 2001, alcançando 35\% em 2009, segundo dados da PNAD 2009. Provavelmente, o maior acesso aos computadores pessoais nos cursos de economia das principais universidades e o surgimento de softwares estatísticos, como Eviews e depois o Stata, tenham facilitado o processo de confecção de artigos econométricos em substituição aos artigos que possuíam estatística descritiva, estes considerados menos matematizados, segundo nossa análise.

A outra mudança que queremos considerar é mais sutil, e certamente requer maiores pesquisas, mas podemos fazer uma primeira aproximação a ela aqui. Essa mudança diz respeito ao caráter geral da academia brasileira de economia e sua relação com a internacional. Podemos aceitar que no começo do período analisado a academia anglo-estadunidense já era fortemente matematizada, apesar de existirem certos segmentos resistentes a esse processo. Ao contrário, no Brasil, como os dados mostram, a economia não matematizada tinha um espaço significativo. Isso era assim apesar de que, desde os anos 1960, no marco da constituição da ANPEC e das mudanças no sistema universitário brasileiro, um número crescente de pesquisadores foi fazer sua pós-graduação no exterior, especialmente nos Estados Unidos e na Inglaterra.

Como mostramos nas seções anteriores, o processo de avanço da matematização já se encontrava lentamente em curso nos anos 1980. Além disso, alguns círculos já trabalhavam prioritariamente com essas abordagens, como vimos no caso da $R B E$.

Entre os diversos fatores que podem ter contribuído para esse processo, queremos destacar um, o impacto da avaliação da CAPES nos cursos de pós-graduação em economia no Brasil. O Sistema de Avaliação da Pós-Graduação foi implantado pela CAPES em 1976. Em seu início esse sistema apenas verificava a titulação dos docentes para fazer avaliação do programa de pós-graduação. A avaliação foi se sofisticando e tornando mais regular posteriormente. Todavia, as avaliações bienais, existentes até 1998, caracterizavam-se pela falta de critérios previamente conhecidos. $\mathrm{Na}$ área de economia, cada comissão, ao ser designada, elaborava os critérios da avaliação que faria do desempenho no biênio anterior.

Em 1998 a CAPES decidiu que a avaliação passaria a ser trienal, e, na área de economia, somente em 2001 a comissão designada para avaliar o período 1998-2000 fez um esforço para estabelecer critérios que fossem estáveis e que servissem também como orientação para futuras avaliações.

Essa comissão se reuniu num primeiro momento para definir "os critérios que norteariam seu trabalho nas etapas posteriores". A Comissão elaborou um documento que detalha os critérios a serem utilizados. Por exemplo, para a classificação dos periódicos nacionais e internacionais, e para atribuição dos seus respectivos pesos, foram criadas cinco categorias de periódicos internacionais e quatro de periódicos nacionais.

Uma das preocupações fundamentais da Comissão de Avaliação da CAPES (2002, p. 1): 
[...] foi a construção de sistemas de avaliação compatíveis com os padrões internacionais da área. $\mathrm{Na}$ área de economia, essa preocupação refletiu-se na política de estímulo a publicações em periódicos internacionais de prestígio. Verificamos a quantidade e regularidade com que os programas da área vêm publicando em tais veículos, bem como a participação nos principais congressos internacionais.

Essa política de estímulo às publicações se refletiu no maior peso atribuído à produção intelectual nos critérios de avaliação dos cursos de pós-graduação em economia da CAPES (2002, p. 1), como podemos verificar abaixo:

$\begin{array}{lc}\text { Ponderação dos Quesitos } & \\ \text { Quesitos } & \text { Pesos } \\ \text { I Proposta do Programa } & \text { Xxx } \\ \text { II Corpo Docente } & 15.00 \\ \text { III Atividade de Pesquisa } & 10.00 \\ \text { IV Atividade de Formação } & 10.00 \\ \text { V Corpo Discente } & 15.00 \\ \text { VI Teses e Dissertações } & 20.00 \\ \text { VII Produção Intelectual } & 30.00\end{array}$

Soma dos Pesos $\quad 100.00$

Notamos que o critério produção intelectual, a partir de 2001 passou a ter um peso de $30 \%$ no total das notas estabelecidas pela CAPES para os cursos de pós-graduação em economia. Podemos concluir daí que a publicação de artigos em periódicos com sistema de pareceristas, e especialmente nos internacionais, foi incentivada e premiada com o peso mais elevado para esse critério de avaliação ${ }^{10}$.

Notamos que, no começo da última década, as comissões de avaliação da CAPES tornam mais claros os critérios de avaliação dos cursos de pós-graduação em economia e dão grande peso ao alinhamento ao padrão de publicação dos principais periódicos internacionais. Essas medidas, além de estimular os grandes centros brasileiros de pós-graduação em economia a esse tipo de publicação, parecem afetar também as publicações nas principais revistas nacionais e nos Encontros da ANPEC. Uma vez que o padrão dos Estados Unidos de publicação é mais matematizado em revistas científicas de economia, e esse padrão domina o cenário internacional, as publicações nas revistas brasileiras teriam seguido no mesmo sentido.

$\mathrm{Na}$ avaliação da CAPES (2004, p. 2) para o triênio 2001-2003 dos cursos de pós-graduação em economia, destaca-se que em seu início as avaliações da CAPES se prendiam "aos requisitos de qualificação e titulação do quadro docente e a uma avaliação qualitativa do nível do programa, transformou-se, ao longo do tempo $e$

\footnotetext{
${ }^{10}$ Considerou-se que a avaliação das "Atividades de pesquisa” deveria ser feita a partir dos seus resultados, ou seja, da produção intelectual, repetindo a nota desse item. Portanto, o peso efetivo da produção intelectual em verdade era de $40 \%$.
} 
segundo as diretrizes da CAPES, em um complexo conjunto de indicadores", como mencionamos na avaliação anterior. O ponto central é novamente a necessidade de se adotar um sistema de avaliação compatível com o padrão internacional. Dentro da necessidade de aproximação e do estímulo causado pelos critérios de avaliação adotados para o triênio 1998-2000, para o triênio 2001-2003 o documento de área da CAPES (2004, p. 2) destaca:

Verificou-se que aumentou a quantidade, a regularidade com que os docentes da área vêm publicando em tais veículos, a participação ativa nos principais congressos internacionais e o intercâmbio de professores e alunos Nota-se também melhoria significativa na qualidade dos veículos em que os trabalhos foram publicados no exterior.

Quanto aos quesitos, foram mantidos em 2004 os mesmos pesos de 2001.

$\mathrm{Na}$ avaliação de 2007 para o triênio 2004-2006, a Comissão da CAPES buscou manter a continuidade dos critérios utilizados nos triênios anteriores. A ênfase novamente foi a de incentivar a internacionalização dos programas da área de economia atribuindo um peso maior à publicação em periódicos internacionais. Para isso, foram estabelecidos critérios absolutos de desempenho para avaliar o grau de internacionalização dos programas da área, com o objetivo de verificar desempenho relativo entre os programas. Nesse sentido, foi atualizado o Qualis da área, com adoção de novo método internacional e reclassificação de "periódicos publicados no país, utilizando-se critérios objetivos para diferenciar os Nacionais dos Locais". Também houve mudanças em termos de pontuação das publicações, elevando o peso para as internacionais. $\mathrm{O}$ total de artigos internacionais publicados, segundo a CAPES (2010, p. 29), foi de 85 no triênio 1998-2000, para 175 entre 2001 e 2003, para 315 no triênio 2004-2006, e para 540 entre 2007 e 2009, um salto em mais de $600 \%$ em 12 anos. A CAPES destaca que o aumento das publicações internacionais foi significativo, visto que foi mais que proporcional à elevação do número de programas e docentes de pós-graduação em economia no país para no período.

Queremos lembrar, finalmente, que apesar dessas mudanças, a situação na academia brasileira de economia ainda é muito diferente da anglo-estadunidense. A presença de mais de $30 \%$ de artigos não matematizados ainda no final dos anos 2000 seria impensável no outro meio intelectual.

\section{CONSIDERAÇÕES FINAIS}

Ao longo deste artigo desenvolvemos conceitos visando verificar o avanço do processo de matematização da ciência econômica dentro da academia brasileira. Por meio da análise qualitativa de 5.733 artigos de três das principais revistas científicas brasileiras de economia e dos Encontros da ANPEC, desde 1981 até 
2010, verificamos que ocorreu um ponto de inflexão no discurso econômico brasileiro em meados da década de 1990.

Nesse ponto de ruptura, os artigos fundamentados principalmente em teoria econômica formalizada com modelos econométricos (tipo iv) e artigos cuja substância é a econometria (tipo v), sem praticamente teoria econômica formalizada, passaram a representar mais de $50 \%$ dos artigos publicados.

Para testar a robustez de nossas definições, analisamos também uma variável quantitativa: equações por artigo, e vimos que houve convergência de trajetória com nossa análise inicial.

Tal processo de avanço da matematização do discurso econômico no Brasil teria duas motivações: primeiro, o progresso técnico, com a proliferação de computadores pessoais na década de 1990 e softwares econométricos, como o Eviews e o Stata. Esses softwares tinham e têm a facilidade de rodarem grande volume de dados. Com isso, a estatística descritiva foi sendo substituída acentuadamente por modelos econométricos. O segundo fator fundamental para o avanço do processo de matematização do discurso econômico no Brasil foi as mudanças ocorridas na CAPES a partir de 2001. Essas mudanças favoreceram as publicações internacionais ao dar grande peso a esse fator na avaliação dos cursos de pós-graduação em economia.

\section{REFERÊNCIAS BIBLIOGRÁFICAS}

BEED, C. \& O. KANE (1991). "What is the Critique of the Mathematization of Economics?”. Kyklos, 44 (4): 581-612.

CAPES (2002). Documento de Área. Área de Avaliação: 28 - Economia. Avaliação trienal 1998-2000. http://www.capes.gov.br/avaliacao/avaliacao-da-pos-graduacao, acesso 7.6.2011.

CAPES (2004). Documento de Área. Área de Avaliação: 28 - Economia. Avaliação trienal 2001-2003.

CAPES (2007). Avaliação Trienal 2004-2006. Documento da área de Economia.

CAPES (2010). Avaliação Trienal 2007-2009. Documento da área de Economia.

COLANDER, D; HOLT, R; ROSSER, B. (2004). "The Changing Face of Mainstream Economics". Review of Political Economy, 16(4): 485-99.

ENCONTRO NACIONAL DE ECONOMIA. http://www.anpec.org.br/encontros.htm, acesso $11 / 7 / 2012$.

GILLIES, D. (2004). "Can mathematics be used successfully in Economics?”. In FULLBROOK, E. (org.) A Guide to What's Wrong with Economics. London: Routledge, pp. 187-197.

INGRAO, B; ISRAEL, G. (1990). The Invisible Hand: Economic Theory in the History of Science. Cambridge: MIT Press.

KATZNER, D. (1991). "In defense of formalization in economics”. Methodus, 3 (1): 17-24.

KRUGMAN, P. (1998). “Two Cheers for formalism”. Economic Journal, 108 (11): 1829-36.

MCCLOSKEY, D (1991). "Economic science: a search through the hyperspace of assumptions?” Methodus, 3 (1): 6-16.

MIROWSKI, P. (1989). More Heat than Light. Cambridge \& New York: Cambridge University Press.

MIROWSKI, P. (1991). "The When, the How and the Why of Mathematical Expression in the History of Economic Analysis”. Journal of Economic Perspectives, 5 (1): 145-157.

PNAD (2009). http://www.ibge.gov.br/home/presidencia/noticias/noticia_visualiza.php?id_noticia $=1708$, acesso 2.8.2011. 
PRADO, E. F. S. (2001). “A ortodoxia neoclássica”. Estudos Avançados, vol. 15, n. 41. São Paulo, janeiro/abril.

RENFRO, C. (2009). “Econometric software”. In D. BELSLEY \& E. KONTOGHIORGES, Eds., Handbook of Computational Econometrics. Chichester: Wiley, pp. 1-54.

SEMINÁRIO DA USP (1997). "Cinquenta Anos de Ciência Econômica no Brasil”. In LOUREIRO, M.R. (org.), Cinquenta Anos de Ciência Econômica no Brasil: Pensamento: Instituições, Depoimentos. Petrópolis: Vozes, pp. 229-313.

WARD, B (1975). Que há de errado com a economia?. RJ: Zahar.

WEINTRAUB, E.R. (1991). Stabilizing Dynamics. New York: Cambridge University Press.

WEINTRAUB, E.R. (1998). “Axiomatisches Missverständnis”. Economic Journal, 108 (11): 1837-47.

WEINTRAUB, E.R. (2002). How Economics Became a Mathematical Science. Durham \& London: Duke University Press.

WOO, H. (1986). What's Wrong with Formalization in Economics: an Epistemological Critique. Newark: Victoria Press. 